\title{
"5 Days in August" - How London Local Authorities Used Twitter during the 2011 Riots
}

\author{
Panagiotis Panagiotopoulos, Alinaghi Ziaee Bigdeli, and Steven Sams \\ Department of Information Systems and Computing \\ Brunel University, London, UK, UB8 3PH \\ \{Panagiotis.Panagiotopoulos, Alinaghi.Ziaee.Bigdeli, \\ Steven.Sams\} @brunel.ac.uk
}

\begin{abstract}
This study examines effects of microblogging communications during emergency events based on the case of the summer 2011 riots in London. During five days in August 2011, parts of London and other major cities in England suffered from extensive public disorders, violence and even loss of human lives. We collected and analysed the tweets posted by the official accounts maintained by 28 London local government authorities. Those authorities used Twitter for a variety of purposes such as preventing rumours, providing official information, promoting legal actions against offenders and organising post-riot community engagement activities. The study shows how the immediacy and communicative power of microblogging can have a significant effect at the response and recovery stages of emergency events.
\end{abstract}

Keywords: Twitter, microblogging, social media, London riots, UK local government, emergency communication, disaster management.

\section{Introduction}

Public authorities are increasing embedding social media in their traditional communications in an attempt to develop and support new types of interactions with citizens e.g. [2], [15]. Microblogging or the practice of sending brief online updates to large audiences seems to be one of the most promising set of tools e.g. [5], [23]. In addition to the prospect of building new relationships with citizens, the immediacy and real-time nature of microblogging services raise a question about their potential to support communication related to emergency or unexpected events.

During emergency events, communication plays a critical role since it can reduce the immediate effects of the crisis, as well as simplify the recovery stage [11]. Particularly in situations that involve public fear and uncertainty, the importance of timely and accurate communication has been highlighted [7]. However, it is common that communication with the public might be disrupted by conflicting or inconsistent information due to factors such as lack of time, high stress, limited resources, difficulties to evaluate the situation and design an appropriate dissemination strategy [7]. Previous studies have examined the enabling role of Twitter (by far the most popular microblogging tool) in emergency events such as the Haiti Earthquake in 
2010 [14], the Australian fire disaster in 2009 [19] and the violent events that took place in USA University campuses in 2010-2011[9].

In this paper, we investigate the use of Twitter as an emergency communication tool from the perspective of local government authorities. Our study takes place in the context of the summer 2011 riots in London. During five days in August 2011, parts of London and other major cities in England suffered from extensive public disorders, violence and even loss of human lives. We identified and collected a total of 699 riotrelated tweets by the official Twitter accounts maintained by 28 London Local Authorities (LAs). The analysis of the tweets indicates those LAs realised the communicative power of Twitter during and beyond the riot events. Not only they were able to control and possibly reduce the immediate effects of the crisis, but they also managed to accelerate the recovery stage by promoting post-riot activities even when disturbances were still in place.

The next section briefly reviews information about Twitter and its use in emergency communication. Section 3 establishes the background of events related to the London riots and sets the scene for the subsequent methodology and analysis sections. The final sections discuss and reflect on the study findings.

\section{Twitter in Emergency Communication}

Despite criticisms such as the one that they might assist in rapidly spreading misleading information, microblogging services are gaining interest among Internet users along with the whole range of social media applications. Twitter was launched in 2006 and its membership base now exceeds 200 million users [13]. Twitter allows its users to post updates of maximum 140 characters via mobile devices, its web interface or desktop applications, e.g. TweetDeck. Twitter messages might contain additional content such as links to websites, photos or videos and they are usually publicly available by default. A Twitter user can follow the stream of messages posted another user, but this connection is not necessarily reciprocal, unlike other social networking sites such as Facebook.

The most distinctive characteristic of Twitter is its immediacy, real-time nature and pace of updating with new content. Although Twitter development sourced from the concept of microblogging, certain conventions using the symbols “@” and "\#” were established by users to support more collaborative and conversational features [10]. The symbol "@” allows users to directly address other users or refer to them in conversations. The symbol "\#” (hashtag) defines streams of tweets that organise discussion about a specific topic or event [20]; for example \#London2012 for London's Olympic Games 2012. Another conversational practice is retweeting i.e. the reproduction of another user's message in its original form or including some small modification or comment. Reasons why users might retweet messages include publicly agreeing or disagreeing with someone, supporting a cause by spreading a message, helping an interesting message reach new audiences or even attempting to gain personal status [3]. 
Research on Twitter has been growing rapidly with studies exploring its effects in areas such as political communication [20] and the organising of collective action [18]. In the public sector, it has been argued that Twitter can assist in reaching new audiences, build relationships with citizens and various stakeholders, as well as broadcast and share information across networks [25]. A few empirical studies found that the communicative patterns of Twitter accounts maintained by governmental agencies are more complicated than simply broadcasting information to as many users as possible [5][23].

During emergency communications, normal use of Twitter is expected to change in terms of both content and frequency of posts [9]. Users are likely to start following new accounts or even join Twitter at the first place; for example, during the riots in England considerably more people started following police accounts [6]. A critical characteristic of Twitter in emergency communications has been the capability to control initial levels of anxiety by providing the public with credible, timely and accurate information [14]. Furthermore, Twitter seems to involve high as a medium in terms of supporting dialogue between users, organising discussions around hashtags, reproducing others' messages and to providing links to other sources. Such flexibility can be exceptionally useful in emergency communication, given the fact that crisis events are rarely identical and tend to generate dissimilar information needs that are difficult to predict [11]. Additionally, it has been suggested that monitoring social media can assist in understanding the emergency situation and level of social tension, with Twitter hashtags being a powerful feature in this direction [14].

Those previous studies have investigated general patterns of Twitter in emergency communication by the full range of Twitter users. Our investigation in the context of the London riots focuses on tweets produced by local government authorities. As suggested in the next section, there has been interest to examine the role of Twitter in reducing the immediate effects of riots (emergency response) and organising post-riot activities (emergency recovery).

\section{Study Background: The Summer 2011 London Riots}

The widespread public disorder in August 2011 was a shocking event in England. The riots across the country lasted for five days. They started in London Tottenham on Saturday 6 August 2011, following protests caused by the death of a local man named Mark Duggan by the London Metropolitan Police two days earlier. From 8th to the 10th of August disorders spread rapidly across London and nationally leading to a total of 66 areas affected, including cities such as Bristol, Manchester and Birmingham.

The official report by the specially formed Independent Riots Communities and Victims Panel [17] states that five people lost their lives and hundreds more lost their businesses and homes in a total estimated cost of over half a billion pounds. About $13,000-15,000$ people were actively involved in the riots. The Home Office reported that more than 5,100 crimes were committed of which the majority $(68 \%)$ occurred 
in London. Crimes committed in London include violence against individuals (217 injuries), arson and criminal damages (over 270 residential and commercial buildings affected), thefts and shop looting (over 300 million pounds loss).

The extent to which the situation in London got out of control during the first three days of rioting is partially blamed on the absence of certain key responsible officials (e.g. the Mayor of London, the Home Secretary) who were on a planned annual leave in the middle of August. One of the key moments in reducing the level of violence in London was the deployment of 16,000 patrolling police forces on the $10^{\text {th }}$ of August. Another important action against the riots was the peace-rally called by Tariq Jahan whose son was killed during the violent disturbances in Birmingham. Moreover, the London Metropolitan Police started a robust campaign to arrest suspected rioters through monitoring more than 200,000 hours of closed circuit television (CCTV) footages.

One of the key issues of the riot events relates to the use of social media. Extensive public debate was generated about whether tools such as Facebook, Twitter and particularly BlackBerry Messenger (BBM) reinforced the riots by rapidly publicising them and even acting as an organising tool [1]. A study by Tonkin et al. [22] shows that Twitter was not used to promote illegal activities, but instead acted more as news broadcasting, information sharing and community organising medium. Tweets during the riots contained information from news agencies, police and other authorities to calling for the public to help individuals, identify suspects, volunteer to clean the streets or raise funds for repairing damaged properties. \#LondonRiots and \#RiotCleanup were among the most popular hashtags [22].

The "Clean-up" campaign was an exceptional campaign proposed by the Mayor of London effort where Londoners encouraged the community to come along with bin bags and brooms for the purpose of cleaning the streets from the disorder caused by looters. Over 60,000 volunteers were mobilised in the most affected areas of London to help local shopkeepers and show solidarity with communities that experienced chaos and violence.

Although London LAs engaged in Twitter-related activity three days after the first incidents happened, it is suggested that their involvement in those activities was dynamic and influential, especially in terms of raising awareness in local communities regarding the situation. For example, on the $12^{\text {th }}$ of August, London LAs, with the help of the Metropolitan Police, released camera images of more than 600 wanted suspects in a blog called "Catch a Looter" that was hosted by Tumbler. In parallel, they used Twitter and Facebook to seek public assistance in identifying those rioters. The London riots point to a fruitful case to study the effects of microblogging in emergency communication from the perspective of local government authorities.

\section{$4 \quad$ Research Methodology}

The findings reported in this paper are part of a wider project which examines the use Twitter in the UK local government based on the official list @ Directgov/ukcouncils that groups the accounts of 191 UK LAs [16]. Those are general accounts, covering 
the whole range of local topics, although some LAs maintain additional more specialised ones for local services such as libraries. The data used in this study were collected in September 2011 using the Twitter developers' database (http://dev.twitter.com/), which is also available for academic research. A total of 21,911 tweets were collected from 28 accounts out of the 33 LAs composing the Greater London administrative area. Most of those accounts were created in 2009 and, at the time of study, they were followed by approximately 1,700 users on average, ranging from 127 to 4,541. Since their creation, they had posted an average of 734 tweets, ranging from 45 to 2,374 .

The investigation of the riot events focused on 699 messages tweeted in the period of 9-12 August 2011. Messages prior and subsequent to these dates were not found to be relevant. Previous studies have discussed the particularities of analysing tweets due to the brief and specific nature of the medium that limits messages to 140 characters and uses the aforementioned conventions to support conversational characteristics [4], [10], [21]. To examine the evolution of collective tweeting activity within the four days, first we conducted a time-series analysis. This was followed by a structural analysis that identified patterns of tweet characteristics in terms of:

- Using the symbol @ as a form of addressivity to refer to other users or directly reply to their messages.

- Using the symbol \# to contribute to discussions organised in hashtags.

- Retweeting messages from other LAs, citizens, the London metropolitan police, media or other organisations.

- The source of tweets (e.g. desktop or mobile device).

At the final stage, we analysed the actual content of the tweets to systematically recognise and classify emerging themes. An open coding grounded approach was used, which has been established as standard for exploratory microblogging studies [8], [9], [12]. Initial communication patterns were derived from the findings of [9], further developed and adapted to the particular case after two rounds of coding in which two coders were involved. The total number of tweets classified in categories is 792 because some of the original 699 were classified in more than one category. The final themes were identified as:

1. Press releases/announcements

2. Statements from the police

3. Information seeking

4. Situation description

5. Preventing rumours

6. Clean-up actions

7. Legal actions

8. Community appraisal

This coding framework serves the specific needs of the study and, along the structural analysis of tweets, provides the opportunity to understand how those Twitter accounts were used during the riots. The next section presents the study findings. 


\section{$5 \quad$ Findings}

This section first presents the general features of the 699 tweets collected from 28 London LAs that tweeted information related to the riots. Next, the results are categorised based on the patterns identified in the dataset.

Tweets by LAs concerning the riots started to spread on the $3^{\text {rd }}$ day of the incidents (i.e. Tuesday $9^{\text {th }}$ August) and continued until Friday $12^{\text {th }}$ August. Table 1 summarises the top 10 authorities with the highest number of tweets during the days of the riots. As explained, most of the incidents took place between the $8^{\text {th }}$ and $9^{\text {th }}$ of August when the disordered behaviours, lootings, damages and so on spread across London and other English major cities causing a domino effect [17]. Therefore, it is not unexpected that more than $70 \%$ of the tweets were posted on the $9^{\text {th }}$. It should be noted that not all London LAs were directly affected by riots. Yet, it is interesting to observe that most of the tweets were dispatched by the one the non-affected authorities i.e. Hillingdon Council, and the least number of tweets belongs to one of the most affected ones i.e. Southwark Council. Another severely affected area was Ealing where 36 messages were posted by the official account during those four days.

Table 1. Top-ten London LAs by number of tweets during the riots. Those not directly affected by the riots are marked with a star.

\begin{tabular}{|lcccc|c|}
\hline \multicolumn{1}{|c}{ London authorities } & $\begin{array}{c}\text { 9 Aug } \\
\text { 2011 }\end{array}$ & 2011 Aug & 11 Aug 2011 12Aug & \multirow{2}{*}{ Total } \\
\hline Hillingdon Council* & 85 & 27 & 18 & 9 & 139 \\
\hline Sutton Council & 29 & 26 & 17 & 5 & 77 \\
\hline Greenwich Council* & 32 & 31 & 7 & 5 & 75 \\
\hline Hounslow Council & 31 & 7 & 2 & 3 & 43 \\
\hline Hammersmith \& Fulham Council* & 10 & 16 & 9 & 3 & 38 \\
\hline Ealing Council & 16 & 8 & 8 & 4 & 36 \\
\hline Wandsworth Council & 19 & 7 & 3 & 4 & 33 \\
\hline Westminster Council & 3 & 10 & 7 & 7 & 27 \\
\hline Barking \& Dagenham Council & 8 & 5 & 5 & 4 & 22 \\
\hline Southwark Council & 3 & 7 & 3 & 7 & 20 \\
\hline
\end{tabular}

Figure 1 illustrates the streams of messages throughout the days in which most of the tweets were posted between $12 \mathrm{pm}$ and $6 \mathrm{pm}$. A peak of 157 tweets was observed in this time frame on the first day after the outburst of disturbances. This was declining steadily in subsequent days to reach about what can be estimated as a normal activity for the middle of August in day 4. 


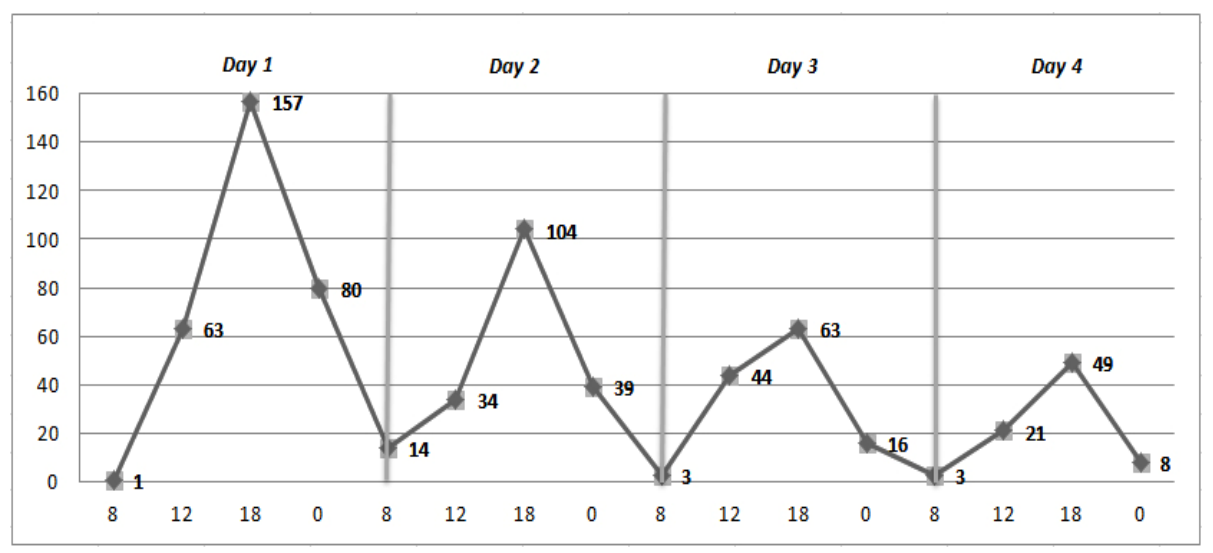

Fig. 1. Time-series of the tweets

About $25 \%$ of all tweets were dispatched after normal office hours; an observation which encouraged the researchers to investigate the sources of tweets as shown in table 2. More than half of the tweets were posted through the web (i.e. twitter.com). About $10 \%$ of the tweets were posted from mobile applications that were normally used outside office hours. Few tweets were referred from twitter-feed, which indicates that the authorities did not use extensively other social media (e.g. Facebook, Flickr, etc.) to feed their tweets. Some tweets not posted from mobile devices still conveyed a live broadcasting tone, for example, the Hillingdon Council tweeted: "Just popped out of the office into Uxbridge town centre. Everyone seems fine and people are going about their day."

Table 2. Sources of tweets

\begin{tabular}{|lcccc|c|}
\hline & $\mathbf{9}$ & $\mathbf{1 0}$ & $\mathbf{1 1}$ & $\mathbf{1 2}$ & \\
& Aug & Aug & Aug & Aug & Total \\
& $\mathbf{2 0 1}$ & $\mathbf{2 0 1 1}$ & $\mathbf{2 0 1}$ & $\mathbf{2 0 1 1}$ & \\
\hline Web & $\mathbf{1}$ & & $\mathbf{1}$ & & \\
\hline Desktop applications & 159 & 117 & 56 & 48 & $380(54.4 \%)$ \\
\hline Mobile applications & 106 & 44 & 29 & 25 & $204(29.2 \%)$ \\
\hline Twitter-feed & 46 & 11 & 10 & 2 & $69(9.8 \%)$ \\
\hline
\end{tabular}

The next stage in the analysis was to examine the mode and trends of tweets. The first entails looking at how authorities engaged directly with citizens by answering their questions via Twitter, as well as how many messages they retweeted from citizens, other LAs, the Metropolitan Police and so on. Also, the analysis captured the number of times messages from the LAs were tweeted. The results of this analysis in table 3 show that the number of replies to other users, mainly requests by citizens, is about $34 \%$ of all tweets. The total times posts by those LAs were retweeted is 730 . 
Table 3. Modes of tweets

\begin{tabular}{|lccccc|c|}
\hline Mode of Tweets & $\mathbf{9}$ & $\mathbf{1 0}$ & $\mathbf{1 1}$ & $\mathbf{1 2}$ & \\
& $\begin{array}{c}\text { Aug } \\
\mathbf{2 0 1 1}\end{array}$ & $\begin{array}{c}\text { Aug } \\
\mathbf{2 0 1 1}\end{array}$ & $\begin{array}{c}\text { Aug } \\
\mathbf{2 0 1 1}\end{array}$ & $\begin{array}{c}\text { Aug } \\
\mathbf{2 0 1 1}\end{array}$ & Total \\
\hline Replies to other users & 122 & 47 & 34 & 23 & 226 \\
\hline Retweeted from citizens & 25 & 18 & 2 & 13 & 58 \\
\hline Retweeted from another LA & 0 & 6 & 8 & 2 & 16 \\
\hline Retweeted from the police & 3 & 9 & 9 & 14 & 35 \\
\hline Retweeted from news agencies & 3 & 6 & 6 & 12 & 27 \\
\hline Total times retweeted by others & 302 & 191 & 126 & 111 & 730 \\
\hline
\end{tabular}

Next, the extent to which LAs are following the UK Twitter trends during the riots was investigated by identifying the use of hashtags. Those hashtags and the number of times appearing in LA tweets are summarised in table 4. Topical hashtags, which group information about a LA, were the most popular. The other four hashtags are among the most popular ones related to the riots as reported by [22].

The final stage was to conduct the content analysis where tweets were classified in 8 thematic categories or patterns with respect to their content. Table 5 shows the distribution of patterns per day. As explained, those patterns are non-exclusive; for example, certain tweets that were classified as press releases or statements by the police also contained situation-describing information. The highest number of tweets during the four days of the riots related to clean-up actions; two examples of tweets in this category are: "Please show your support for our local businesses - shop local \#cleanup" and "Clean up volunteers show true spirit of borough".

Table 4. Following trends through hashtags

\begin{tabular}{|lcccc:c|}
\hline Following Trends & $\begin{array}{c}\mathbf{9} \\
\text { Aug }\end{array}$ & $\begin{array}{c}\mathbf{1 0} \\
\text { Aug }\end{array}$ & $\begin{array}{c}\mathbf{1 1} \\
\text { Aug }\end{array}$ & $\begin{array}{c}\mathbf{1 2} \\
\text { Aug }\end{array}$ & Total \\
& $\mathbf{2 0 1 1}$ & $\mathbf{2 0 1 1}$ & $\mathbf{2 0 1 1}$ & $\mathbf{2 0 1 1}$ & \\
\hline \#LondonRiots & 12 & 21 & 6 & 7 & 46 \\
\hline \#StaySafe & 1 & 2 & 0 & 0 & 3 \\
\hline \#RiotCleanup & 3 & 14 & 9 & 7 & 33 \\
\hline \#WitnessAppeal & 0 & 0 & 21 & 20 & 41 \\
\hline \#[Name of the council] & 11 & 29 & 14 & 19 & 73 \\
\hline
\end{tabular}

This large number of posts seems to have encouraged individuals and groups to organise large scale clean-ups after the riots and actively support their communities. It was also related to the 143 posts that praised local communities about their quick and effective response to the call of action; even the phrase "the riot heroes" was frequently used in tweets to thank local citizens involved in those activities. Examples of tweets in this category are: "Thanks again to all who turned up at \#Camden this morning to help clean up. Great to see the community coming together 
and helping out" and "200+ people prepare to clean up \#Clapham Junction. Boris [Mayor of London] says it's 'London Fighting Back'. Thanks to everyone!”.

Table 5. Distribution of tweet patterns

\begin{tabular}{|lcccccc|}
\hline Tweets Patterns & $\begin{array}{c}\mathbf{9} \\
\text { Aug }\end{array}$ & $\begin{array}{c}\mathbf{1 0} \\
\mathbf{A u g}\end{array}$ & $\begin{array}{c}\mathbf{1 1} \\
\mathbf{A u g}\end{array}$ & $\begin{array}{c}\mathbf{1 2} \\
\text { Aug }\end{array}$ & Total & $\begin{array}{c}\text { \% of } \\
\text { all } \\
\text { tweets }\end{array}$ \\
\hline Press Release & 29 & 31 & 22 & 11 & 93 & $13.3 \%$ \\
\hline Police Statement & 14 & 24 & 16 & 6 & 60 & $8.6 \%$ \\
\hline Information Seeking & 9 & 17 & 23 & 0 & 49 & $7.0 \%$ \\
\hline Situation Description & 48 & 26 & 35 & 26 & 135 & $19.3 \%$ \\
\hline Preventing Rumours & 44 & 14 & 0 & 1 & 59 & $8.4 \%$ \\
\hline Clean-up Actions & 114 & 31 & 0 & 2 & 147 & $21.0 \%$ \\
\hline Legal Actions & 3 & 39 & 41 & 23 & 106 & $15.2 \%$ \\
\hline Community Appraisal & 77 & 23 & 19 & 24 & 143 & $20.5 \%$ \\
\hline
\end{tabular}

About $22 \%$ of all tweets concerned press releases or official police statements. Press releases included official announcements by the authorities as well as statements by local elected representatives. Usually, a link to the full announcement to the LA's website or other online sources was included in the tweet.

Another important pattern identified mainly within the first two days was "preventing rumours" through direct replies to tweets by other users or pro-active announcements. This was also a response to the fact that several people tweeted false and untrue information about the situation resulting possibly in an increase of the level of anxiety. For instance, the Hounslow Council posted: "If people only tweet what they actually see as opposed to what they have heard in \#hounslow then we will have a clear picture". On the same day, the Hammersmith and Fulham Council tweeted: "Reporting calm in $H \& F$ [Hammersmith \& Fulham]. Please question rumors rather than spread them. \#londonriots \#Hammersmith \#Fulham \#ShepherdsBush".

The number of tweets regarding information seeking and legal actions was also noteworthy. For example, one of the most affected authorities posted: "We've just uploaded CCTV images of people wanted for questioning over disturbances. Pls help up find them.". Another tactic in this direction was to tweet information about legal actions happening even during the riots, for example Greenwich Council retweeted a message from the Metropolitan Police stating: "We have started knocking on doors to arrest people. We arrested a total of 888 people in connection with disorders". This message was retweeted 127 times by other users (e.g. citizens, other councils, etc.).

\section{Discussion}

Regular Twitter use is expected to change (even radically) during emergency events [9]. In our dataset, this was noticeable both in the sudden increase in the volume and frequency of messages, as well as in the particular topics on which London LAs 
focused their tweets. An average posting activity of those accounts is normally not more than 10 tweets per day and usually concerns a wide range of local issues. Interestingly, we found very high activity generated by certain LAs that were not directly affected by social unrest, combined with low activity by some of those that were severely affected. Such an asymmetry cannot be fully understood within the scope of this study, yet it might point to more localised factors about how those accounts are administrated. For example, LAs such as Hillingdon and Greenwich, even though not directly affected by riots, increased their number of tweets by responding to citizen queries in addition to making formal announcements.

On the basis of the previous studies discussed in section 2, it is reasonable to expect that an interactive real-time tool such as Twitter could be useful for LAs in their effort to handle communications with the public during the riots. The findings support this case by revealing specific mechanisms related to the emergency response and recovery stages.

At the response stage, Twitter was used for reducing the immediate effects of the crisis in terms of preventing rumours, responsibly informing the public and spreading the information about legal actions in progress. Twitter also seems to have extended communication beyond official working hours and spaces, for example through the use of mobile devices. While providing timely, accurate and credible information is of apparent importance [14], spreading the news about legal actions in progress seems to be a more innovative use that is likely to have contributed in controlling social disorder. This is because most of those involved in the incidents across the country were youngsters [17], therefore more eager to come across information on social networking tools.

Furthermore, the role of Twitter was evident in terms of accelerating and simplifying the recovery stage of the riots. This was achieved very shortly after the riots had taken place by: (1) organising community support activities and (2) regularly praising citizens participating in those events. In this respect, Twitter seems to have reinforced grassroots community action and the rapid mobilisation of available resources by LAs and individuals. Indeed, according to [24], community collaboration and the ability to think outside traditional command and control hierarchies can be a successful element of emergency recovery.

The later also raises a question about the duties that local government officers had to assume during the riots, also given the fact that the events happened in the middle of August when certain officials were on annual leave. This might explain why some accounts tweeted asymmetrically less than expected and possibly suggest that officials administrating Twitter accounts had to assume increased public relations responsibility than regularly. Therefore, in certain cases of very active of LAs, it is difficult to distinguish whether their innovative use of Twitter was a pre-planned strategic effort or simply the result of ad hoc creative behaviour by officers.

The practical implications of this study reveal some elements of good practice in public sector microblogging during emergency commutations. However, potential improvements can be observed in the way LAs used Twitter during the riots. First of all, it seems that LAs were quite slow in their initial response, with no relevant tweets found in the period of 6-8 August. Furthermore, the use of hashtags was not 
extensive, hence resulting in reducing the visibility of tweets since hashtags are critical in building an ad hoc space to monitor a topic [9].

Those two aspects reinforce previous suggestions that authorities should make consistent effort to enhance the level of education and awareness of officers communicating with the public using social media [19].

\section{Conclusion}

This paper examined the role of microblogging during the summer 2011 riots in London by analysing 699 riot-related tweets posted by 28 London LAs between the $9^{\text {th }}$ and $12^{\text {th }}$ August. The findings indicate increased use of Twitter during the riots to support the deployment of several anti-riot mechanisms at the response and recovery stages. Those mechanisms were enabled by the conversational and communicative elements of Twitter such as the ability to retweet messages or group discussions through hashtags. Therefore, the London riots seem to provide certain evidence that Twitter can be used as a significant extension of traditional emergency communication.

Nevertheless, fully assessing such as a claim might not be possible given the limitations of this study. This is because we focused only on tweets posted by London LAs without a broader examination of other information channels that those LAs might have used during the riots. Apart from a cross-examination of other sources, the analysis could also be expanded to riot-related tweets by citizens, police authorities, news agencies and so on. Further research on microblogging communications can certainly elaborate on some of those aspects in the context of unexpected events.

\section{References}

1. BBC: English Riots: Social Media were 'Force for Good' (2011), http: / / www . bbc. co.uk/news / uk-politics-14931010 (accessed June 15, 2012)

2. Bertot, J.C., Jaeger, P.T., Hansen, D.: The Impact of Polices on Government Social Media Usage: Issues, Challenges, and Recommendations. Government Information Quarterly 29, 30-40 (2012)

3. Boyd, D., Golder, S., Lotan, G.: Tweet, Tweet, Retweet: Conversational Aspects of Retweeting on Twitter. In: 43rd Hawaii International Conference on System Sciences, pp. 1-10 (2010)

4. Bruns, A.: How Long is a Tweet? Mapping Dynamic Converstation Networks on Twitter using Gawk and Gephi. Information, Communication \& Society (in press)

5. Cho, S.E., Park, H.W.: Government Organizations' Innovative use of the Internet: The Case of the Twitter Activity of South Korea's Ministry for Food, Agriculture, Forestry and Fisheries. Scientometrics 90, 9-23 (2012)

6. Crump, J.: What are the Police Doing on Twitter? Social Media, the Police and the Public. Policy \& Internet 3, 1-27 (2011)

7. Hale, J.E.: Crisis Response Communication Challenges: Building Theory from Qualitative Data. Journal of Business Communication 42, 112-134 (2005) 
8. Heverin, T., Zach, L.: Twitter for City Police Department Information Sharing. Proceedings of the American Society for Information Science and Technology 47, 1-7 (2010)

9. Heverin, T., Zach, L.: Use of Microblogging for Collective Sense-Making during Violent Crises: A Study of Three Campus Shootings. Journal of the American Society for Information Science and Technology 63, 34-47 (2012)

10. Honey, C., Herring, S.C.: Beyond Microblogging: Conversation and Collaboration Via Twitter. In: 42nd Hawaii International Conference on System Sciences, pp. 1-10 (2009)

11. Horsley, J.S., Barker, R.T.: Toward a Synthesis Model for Crisis Communication in the Public Sector: An Initial Investigation. Journal of Business and Technical Communication 16, 406-440 (2002)

12. Jansen, B.J., Zhang, M., Sobel, K., et al.: Twitter Power: Tweets as Electronic Word of Mouth. Journal of the American Society for Information Science and Technology 60, 2169-2188 (2009)

13. Mashable, A.: Visual History of Twitter (2011), http: //mashable.com/2011/09/30/twitter-history-infographic/

14. Oh, O., Kwon, K.H., Rao, H.R.: An Exploration of Social Media in Extreme Events: Rumor Theory and Twitter during the Haiti Earthquake. In: Proceedings of the International Conference on Information Systems (2010)

15. Osimo, D.: Web 2.0 in Government: Why and how? JRC Scientific and Technical Reports (2008)

16. Panagiotopoulos, P., Sams, S.: An Overview Study of Twitter in the UK Local Government, Transforming Government Workshop, Brunel University, London (2012)

17. Riots Panel: 5 Days in August: An Interim Report on the 2011 English Riots (2011)

18. Segerberg, A., Bennett, W.L.: Social Media and the Organization of Collective Action: Using Twitter to Explore the Ecologies of Two Climate Change Protests. The Communication Review 14, 197-215 (2011)

19. Sinnappan, S., Farrell, C., Stewart, E.: Priceless Tweets! A Study on Twitter Messages Posted during Crisis: Black Saturday. In: Proceedings of the Australasian Conference on Information Systems (2010)

20. Small, T.A.: What the Hashtag? A Content Analysis of Canadian Politics on Twitter. Information, Communication \& Society 14, 872-895 (2011)

21. Takhteyev, Y., Gruzd, A., Wellman, B.: Geography of Twitter Networks. Social Networks 34, 73-81 (2012)

22. Tonkin, E., Pfeiffer, H.D., Tourte, G.: Twitter, Information Sharing and the London Riots? Bulletin of the American Society for Information Science and Technology 38, 49-57 (2012)

23. Waters, R.D., Williams, J.M.: Squawking, Tweeting, Cooing, and Hooting: Analyzing the Communication Patterns of Government Agencies on Twitter. Journal of Public Affairs 11, 353-363 (2011)

24. Waugh, W.L., Streib, G.: Collaboration and Leadership for Effective Emergency Management. Public Administration Review 66, 131-140 (2006)

25. Wigand, F.D.: Twitter Takes Wing in Government: Diffusion, Roles, and Management. In: Proceedings of the 11th Annual International Digital Government Research Conference on Public Administration Online: Challenges and Opportunities, pp. 66-71 (2010) 